九州大学学術情報リポジトリ

Kyushu University Institutional Repository

\title{
Effect of Inhibition of Proteasome-Mediated Proteolysis on Ligninolytic Activities of White-Rot Fung $\mathrm{i}$
}

Cho, Nam-Seok

Wood and Paper Science, Chungbuk National University

Staszczak, Magdalena

Department of Biochemistry, Maria Curie-Sklodowska University

Rogalski, Jerzy

Laboratory of Forest Resources Management, Division of Forest Ecosphere Management, Department of Forest and Forest Products Sciences, Kyushu Unviversity | Department of Biochemistry, Maria Curie-Sk lodowska University

Cho, Hee-Yeon

Molecular Microbiology and Immunology, Keck School of Medicine, University of Southern California

他

https://doi.org/10.5109/12848

出版情報：九州大学大学院農学研究院紀要. 53 (2)，pp. 399-404，2008-10-28. Faculty of Agriculture, Kyushu University

バージョン :

権利関係 : 


\title{
Effect of Inhibition of Proteasome-Mediated Proteolysis on Ligninolytic Activities of White-Rot Fungi
}

\author{
Nam-Seok CHO $^{1}$, Magdalena STASZCZAK ${ }^{2}$, Jerzy ROGALSKI ${ }^{2}$, \\ Hee-Yeon $\mathrm{CHO}^{3}$ and Shoji OHGA*
}

\author{
Laboratory of Forest Resources Management, Division of Forest Ecosphere Management, \\ Department of Forest and Forest Products Sciences, Kyushu University, \\ Sasaguri, Fukuoka 811-2415, Japan \\ (Received June 23, 2008 and accepted July 16, 2008)
}

\begin{abstract}
It has recently been established that most short- and long-lived cellular proteins (80-90\%) are degraded by a highly selective non-lysosomal pathway that requires ATP and a large ( 2.5 MDa) multisubunit, multicatalytic proteinase complex known as the $26 \mathrm{~S}$ proteasome. It degrades many important proteins involved in signaling pathway, in cell cycle control, and in general metabolism, including transcription factors and key metabolic enzymes. Here, we demonstrated all distinct proteasome activities: chymotrypsinlike, trypsin-like, and caspase-like (peptidylglutamyl-peptide hydrolyzing) in mycelial extracts of the white-rot fungi Trametes versicolor and Phlebia radiata by monitoring cleavage of three different fluorogenic peptide substrates: Suc-LLVY-MCA, Z-GGR-MCA, Z-LLE- $\beta$ NA, respectively. We also found that this cleavage was ATP-dependent. Reagents that inhibit proteasome-mediated protein degradation in intact cells have recently become available, including substrate-related peptide aldehydes. These inhibitors are useful tools to demonstrate that a process exhibits proteasome-dependent biochemical regulation. In the present study, we report that in vivo Cbz-LLLal treatment strongly inhibited all tested proteasome activities and affected ligninolytic activities in nutrient deprived cultures of both fungi.
\end{abstract}

\section{INTRODUCTION}

For many years proteolysis has been considered to be a nonspecific process mainly involved in basal protein turnover. Our knowledge of intracellular protein degradation advanced considerably during the past two decades. Intracellular proteolysis is the most recently discovered regulatory system of cellular physiology. It is clear now that degradation of cellular proteins is a highly complex, temporally controlled, and tightly regulated process. In eukaryotic cells protein degradation occurs via two pathways: a lysosomal (vacuolar) pathway and a non-lysosomal (non-vacuolar) pathway. The latter includes: proteasomes, calpains and organellar proteases.

It has recently been established that most shortand long-lived cellular proteins (80-90\%) are degraded by a highly selective non-lysosomal pathway that requires ATP and a large ( 2.5 MDa) multisubunit, multicatalytic proteinase complex known as the 26S proteasome (Coux et al., 1996; Goldberg et al., 1997; Rechsteiner, 1998; Voges et al., 1999; Glickman and Ciechanover, 2002; Pickart et al., 2004). The $26 \mathrm{~S}$ proteasome consists of a barrel-shaped proteolytically active core (20S proteasome) and one or two 19S regulatory complexes attached to the outer surface of the core particle. These com-

${ }^{1}$ Wood and Paper Science, Chungbuk National University, Cheongju 361-763, Korea

${ }^{2}$ Department of Biochemistry, Maria Curie-Sklodowska University, Plac M. Curie-Sklodowskiej 3, Pl 20-031 Lublin, Poland

Molecular Microbiology and Immunology, Keck School of Medicine, University of Southern California, Los Angeles, CA 90089, USA

* Corresponding author (E-mail: ohga@forest.kyushu-u.ac.jp) plexes associate together in an ATP-dependent manner. The 20S proteasome is arranged as four axially stacked rings with two central rings of seven distinct -subunits and two distal rings composed of seven distinct -type subunits $\left(\alpha_{1-7} \beta_{1-7} \beta_{1-7} \alpha_{1-7}\right)$.

The proteasome's multiple catalytic sites are located within the internal cavity of the -subunits. These catalytic sites are classified based on their specificity toward short synthetic peptides. Two termed 'chymotrypsinlike' cut preferably after hydrophobic residues and are located on the $\beta_{5}$ subunits. Two 'trypsin-like' sites, located on the $\beta_{2}$ subunits, cleave after basic amino acids. The two remaining sites, located on the $\beta_{1}$ subunits, are referred to as peptidylglutamyl-peptide hydrolyzing ('post-acidic', 'caspase-like') (Kisselev et al., 1999). These names are used to indicate their general similarities to the substrate specificities of 'classical' proteases, though they do not imply any similarity in catalytic mechanisms or physiological functions. Unlike all other known proteases, the proteasome uses nucleophilic $\mathrm{N}$-terminal threonine residues in catalysis (Seemüller et al., 1995).

The $20 \mathrm{~S}$ proteasome is a unique multicatalytic enzyme whose multiple catalytic sites function only as an integral part of this particle and degrade proteins in a processive fashion without the release of polypeptide intermediates into the cytoplasm. The proteolytic chamber of the 20S proteasome is accessible only to unfolded protein substrates through a narrow channel leading from the surface of the $\alpha$-rings. The majority of substrates targeted for degradation by the proteasome are marked by covalent attachment of chains containing of at least four molecules of G76-K48 isopeptide-linked ubiquitin (Ub) (Thrower et al., 2000), a small (76 residue) evolutionarily conserved protein found in all 
eukaryotic cells (Pickart, 1998). Ubiquitination involves the sequential action of the Ub activating enzyme (E1), a Ub conjugating enzyme (E2), and a Ub-protein ligase (E3). Ubiquitin and ATP dependence to proteolysis is conferred by the $19 \mathrm{~S}$ regulatory complex comprising of at least 18 different subunits that include 6 ATP-ases, polyubiquitin binding sites, and isopeptidases. After binding to the proteasome, polyubiquitinated protein conjugates are unfolded, translocated into the proteolytic core, deubiquitinated, and degraded into small peptides.

The presence of the proteasome pathway has been documented in all eukaryotes examined for it, including mammals, plants, fish, parasites, and yeast. During the past decade, the $26 \mathrm{~S}$ proteasome found both in the cytosol and nucleus, was shown to play vital regulatory functions. It degrades many important proteins involved in signaling pathway, in cell cycle control, and in general metabolism, including transcription factors and key metabolic enzymes.

White-rot fungi are mostly known as excellent degraders of lignin. These microorganisms are able to degrade lignin by producing extracellular enzymes, the best characterized of which are laccase, lignin peroxidases, and manganese peroxidases (Eriksson, 1990). Lignin-modifying enzymes of white-rot fungi are mainly expressed during secondary metabolism (i.e. idiophase) in response to environmental triggers such as C- or nitrogen starvation (Keyser et al., 1978; Jeffries et al., 1981). Recent studies revealed that intracellular proteolysis plays an essential role in response to stress conditions such as nutrient deprivation or high temperatures (Hilt and Wolf, 1992). It has been demonstrated for many eukaryotic organisms, including yeasts, that both the lysosomal (vacuolar) and non-lysosomal (non-vacuolar) proteolytic systems are activated by nutrient starvation (Hilt and Wolf, 1992; Cuervo and Dice, 1998).

While lignin degradation by the white-rot fungi long has been studied, very little has yet been done on proteolytic systems of these organisms. Studies on proteases of the white-rot fungi have been confined mainly to extracellular enzymes (Eriksson and Pettersson, 1988; Dosoretz et al., 1990; Dey et al., 1991; Datta, 1992; Dass et al., 1995; Staszczak et al., 1996; Cabaleiro et al., 2002), intracellular proteolysis is less well explored (Staszczak et al., 1996; Lilly et al., 1994; Wadekar et al., 1995). The presence of multiple intracellular and extracellular proteolytic activities in cultures of the white-rot fungi Trametes versicolor and Phlebia radiata have been previously demonstrated in our laboratory (Staszczak et al., 1996). Native PAGE with copolymerized denatured hemoglobin as a substrate revealed changes in patterns of secreted and mycelial proteases upon carbon or nitrogen starvation. We have subsequently investigated the possibility of proteinases, intracellular and extracellular, being involved in the regulation of ligninoltyic activities of Trametes versicolor (Staszczak et al., 2000). On the basis of our previous findings on the ability of mycelial extracts of Trametes versicolor and Phlebia radiata to hydrolyze Suc-Leu-
Leu-Val-Tyr-4-methylcoumaryl-7-amide (SucLLLVYMCA), a well known substrate used to detect chymotrypsin-like activity of the proteasome (Staszczak, 2002), it was deemed important to study whether all distinct proteasome activities: chymotrypsin-like, trypsin-like, and caspase-like, are simultaneously detectable in these fungi. Here, we demonstrated these activities by monitoring cleavage of three different fluorogenic peptide substrates and found that this cleavage was ATPdependent. Recently, reagents that inhibit proteasomemediated protein degradation in intact cells have become available, including substrate-related peptide aldehydes. In the present study, we report that in vivo Cbz-LLLal treatment strongly inhibited all tested proteasome activities and affected ligninoltyic activities in nutrient deprived cultures of both fungi.

\section{MATERIALS AND METHODS}

\section{Culture condition}

Culture conditions were essentially those described previously (Staszczak et al., 2000). Mycelia of the white-rot fungi Trametes versicolor (ATCC 44308) and Phlebia radiata (ATCC 64658) were maintained, through periodic (every 7 days) inoculation with floating discs of mycelium ( $5 \mathrm{~mm}$ of the diameter) as surface cultures at $26^{\circ} \mathrm{C}$, in scintillation flasks containing $10 \mathrm{ml}$ of nutrient-rich growth medium with glucose (20 g/l) as a carbon (C) source and L-asparagine (19 mM) as a nitrogen $(\mathrm{N})$ source.

After the 7-day cultivation period, mycelia were transferred to flasks containing $2 \mathrm{ml}$ of the fresh growth media deprived of glucose (C-starvation) or L-asparagine (N- starvation), and the incubation at $26{ }^{\circ} \mathrm{C}$ continued for 6 hours. The mycelia were washed twice with $5 \mathrm{ml}$ portions of the relevant medium, before being transferred to the media deprived either of glucose or L-asparagine. The trophophasic media (non-starved cultures) in transfer experiments contained glucose and asparagine of the same concentrations as those measured after seven days of fungal growth. The other components were the same as in the nutrient-deprived media; washing was also applied. The concentration of glucose in nitrogen deprived media as well as the concentration of L-asparagine in C-depleted media were the same as corresponding concentrations measured after 7-day cultivation period. Three independent experiments were performed in duplicate.

\section{In vivo MG 132 treatment}

The proteasome inhibitor carbobenzoxy-Leu-Leuleucinal (MG 132) in dimethyl sulfoxide (DMSO) was added to a final concentration of $40 \mu \mathrm{M}$ at the time of transfer of mycelia to the nutrient-deprived or trophophasic media. An equivalent amount of solvent used (DMSO) was added to parallel sets of cultures (nutrientdeprived and trophophasic). At 6 hours after exposure to the inhibitor, enzymatic activities were assayed by the methods described below. The results are expressed as a percentage of remaining activity. For each determina- 
tion, the specific activity (per mg of protein) of samples from the parallel culture $\mathrm{C}$-deprived, $\mathrm{N}$-deprived and trophophasic) without the inhibitor was taken to be $100 \%$.

\section{Preparation of extracellular culture fluid}

Extracellular samples were collected by separating culture fluid from mycelium by filtration. The filtrates were desalted through a Sephadex G-25 column. The elution was performed with 0.001 M Tris, pH 7.0.

\section{Preparation of mycelial extracts}

Mycelia were harvested and homogenized in an icechilled motor-driven Potter's homogenizer, in $3 \mathrm{ml}$ of $0.05 \mathrm{M}$ Tris-HCl buffer, $\mathrm{pH} 7.3$, containing $0.005 \mathrm{M} \mathrm{MgCl}_{2}$. The homogenates were then centrifuged for $10 \mathrm{~min}$ at $10000 \times \mathrm{g}$, at $4^{\circ} \mathrm{C}$. The supernatants were desalted through a Sephadex G-25 column as described above.

\section{Proteasome assasy}

Activities of the $26 \mathrm{~S}$ proteasome were detected in mycelial extracts by monitoring cleavage of three different fluorogenic peptide substrates: Suc-Leu-Leu-ValTyr-7-amido-4-methylcoumarin (Suc-LLVY-AMC), Z-Gly-Gly-Arg-7-amido-4-methylcoumarin (Z-GGRAMC) and Z-Leu-Leu-Glu-2-naphtylamide (Z-LLE$\beta \mathrm{NA}$ ) for chymotrypsin-like, trypsin-like, and caspaselike (peptidylglutamyl-peptide hydrolyzing) activity, respectively. The modified stopped procedure was performed essentially as described previously. Briefly, $100 \mu \mathrm{l}$ assay mixtures containing $10-25 \mu \mathrm{l}$ of the mycelial extract (7 14 $\mu \mathrm{g}$ of protein), $100 \mu \mathrm{M}$ substrate (in DMSO), $100 \mathrm{mM}$ Tris-HCl buffer (pH 8.0), $2 \mathrm{mM}$ ATP, $5 \mathrm{mM} \mathrm{MgCl}_{2}$, were incubated at $37^{\circ} \mathrm{C}$ for 30 and $60 \mathrm{~min}$. Reactions were stopped by addition of $100 \mu \mathrm{l}$ of $10 \%$ SDS (w/v) and $2.0 \mathrm{ml}$ of $0.1 \mathrm{M}$ Tris-HCl buffer, $\mathrm{pH} 9.0$. Blanks were prepared without the addition of enzyme. The fluorescent proteolysis products were quantified in a spectrofluorometer (FluoroMax-2, Instruments S.A., Inc., JOBIN YVON/SPEX Division, USA), with an excitation wavelength of $360 \mathrm{~nm}$ and an emission wavelength of $440 \mathrm{~nm}$ for MCA-substrates or an excitation wavelength of $335 \mathrm{~nm}$ and an emission wavelength of $410 \mathrm{~nm}$ for NA-substrate.

\section{Determination of laccase activity (EC 1.10.3.2)}

Activity of laccase (benzenediol : oxygen oxidoreductase) was determined in desalted samples of culture filtrates (Leonowicz and Grzywnowicz, 1981) using syringaldazine as a substrate. $0.1 \mathrm{M}$ citrate- $\mathrm{NaOH}$ buffer, pH 5.0 was used for determinations. Specific activity was calculated with the extinction coefficient of $65,000 \mathrm{M}^{-1} \mathrm{~cm}^{-1}$ and expressed in nanokatals per milligram of protein.

\section{Determination of peroxidase activity (EC 1.11.1.7)}

Peroxidase activity was assayed in desalted samples of culture filtrates (Claiborne and Fridovich, 1979). $0.003 \% \quad \mathrm{H}_{2} \mathrm{O}_{2}, 0.01 \%$ o-dianisidine, and $0.1 \mathrm{M}$ citrate$\mathrm{NaOH}$ buffer, $\mathrm{pH} 5.0$, were used for determinations.
Specific activity was expressed in nkat per milligram of protein; $\varepsilon$ used for calculations was $29,300 \mathrm{M}^{-1} \mathrm{~cm}^{-1}$.

\section{Determination of protein}

Protein concentration was measured according to the method described by Lowry and modified by Schacterle and Pollack (1973). Bovine serum albumin was used as standard.

\section{RESULTS AND DISCUSSION}

To date, proteasomes from other than animal or plant cells were studied only in yeast (Chen and Hochstrasser, 1995; Glickman et al., 1998; Fujimuro et al., 1998). Our research is, to our best knowledge, the first attempt to detect multiple proteolytic activities attributed to proteasomes in basidiomycete fungi. We demonstrated all distinct proteasome activities: chymotrypsin-like, trypsin-like, and caspase-like (peptidylglutamyl-peptide hydrolyzing) in mycelial extracts of the white-rot fungi Trametes versicolor and Phlebia radiata by monitoring cleavage of three different fluorogenic peptide substrates: Suc-LLVY-MCA, Z-GGR-MCA, Z-LLE- $\beta$ NA, respectively. We also found that the cleavage of substrates used was significantly stimulated by MgATP. Thus, assay mixtures were supplemented with ATP and $\mathrm{MgCl}_{2}$ (for details see Materials and Methods).

The lack of specific cell-permeable inhibitors of the proteasome pathway has long been a major factor limiting an understanding of its function in vivo. Substraterelated peptide aldehydes were the first proteasome inhibitors to be developed and are still the most widely used inhibitors (Lee and Goldberg, 1998; Kisselev and Goldberg, 2001). More specific inhibitors of the proteasome, such as lactacystin $\beta$-lactone or epoxomicin are too expensive for most in vivo experiments.

MG 132 (carbobenzoxy-Leu-Leu-leucinal, also termed Z-Leu-Leu-Leu-al or Cbz-LLL) is the most potent and selective of commercially available aldehydes. It is considered to be the first choice to study proteasome involvement in a process in intact cells (Kisselev and Goldberg, 2001). In the present study, we used MG 132 as the proteasome inhibitor in cultures of Trametes versicolor and Phlebia radiata and examined its effect on distinct proteasome activities: chymotrypsin-like, trypsinlike, and caspase-like under $\mathrm{C}$ - or $\mathrm{N}$ - starvation. We also tested whether the exposure of mycelia to this agent can lead to changes in activity of ligninolytic enzymes upon nutrient limitation. To assess its effect on fungal metabolism, MG 132 was added to cultures of the fungi at the time of transfer of mycelia to the nutrient-deprived or trophophasic media.

In this study, all three catalytic activities of the proteasome were inhibited by MG 132 treatment, but to different degrees (Table 1 and Table 3). MG 132 is known to act predominantly on the chymotrypsin-like activity but also has been found to have some, usually weaker, effects on the two other sites: trypsin-like and caspaselike. The three peptidase activities of $T$. versicolor were inhibited in a conditions dependent fashion (Table 1). 
Table 1. Effect of in vivo proteasome inactivation on proteasome activities in mycelial extracts of Trametes versicolor

\begin{tabular}{|c|c|c|c|c|}
\hline \multirow[b]{2}{*}{ Culture $^{1}$} & \multirow[b]{2}{*}{ Treatment } & \multicolumn{3}{|c|}{ Relative activity (\% of control) ${ }^{2}$} \\
\hline & & $\begin{array}{l}\text { Chymotrypsin- like } \\
\text { (SucLLVY-AMC) }\end{array}$ & $\begin{array}{c}\text { Trypsin- like } \\
\text { (Z-GGR-MCA) }\end{array}$ & $\begin{array}{c}\text { Caspase- like } \\
\text { (Z- LLE- } \beta \text { NA) }\end{array}$ \\
\hline Non-starved & $\begin{array}{l}\text { None } \\
\text { MG } 132\end{array}$ & $\begin{array}{c}100 \\
65 \pm 7\end{array}$ & $\begin{array}{c}100 \\
78.5 \pm 6\end{array}$ & $\begin{array}{c}100 \\
81 \pm 11\end{array}$ \\
\hline $\mathrm{C}$ - starved & $\begin{array}{l}\text { None } \\
\text { MG } 132\end{array}$ & $\begin{array}{c}100 \\
31 \pm 8\end{array}$ & $\begin{array}{c}100 \\
61 \pm 9\end{array}$ & $\begin{array}{c}100 \\
48 \pm 16\end{array}$ \\
\hline $\mathrm{N}$ - starved & $\begin{array}{c}\text { None } \\
\text { MG } 132\end{array}$ & $\begin{array}{c}100 \\
36.5 \pm 6\end{array}$ & $\begin{array}{c}100 \\
55 \pm 7.5\end{array}$ & $\begin{array}{c}100 \\
60 \pm 5\end{array}$ \\
\hline
\end{tabular}

${ }^{1}$ After seven days of growth on nutrient- rich media mycelia were transferred to media deprived of glucose (C- starvation) or L- asparagine (N- starvation) and to trophophasic media (for details see "Materials and Methods"). Enzymatic activities were assayed after $6 \mathrm{hr}$ of exposure to the proteasome inhibitor, MG 132 (Cbz- LLLal).

${ }^{2}$ The specific activity (per mg of protein) of samples from the parallel culture (C- deprived, Ndeprived, or trophophasic) without the inhibitor was taken to be $100 \%$.

Table 2. Effect of in vivo proteasome inactivation on ligninolytic activities in cultures of Trametes versicolor

\begin{tabular}{cccc}
\hline \multirow{2}{*}{ Culture $^{1}$} & Treatment & \multicolumn{2}{c}{ Relative activity (\% of control) $^{2}$} \\
\cline { 3 - 4 } Non-starved & None & Laccase & Peroxidase \\
\hline \multirow{2}{*}{ C-starved } & MG 132 & $109 \pm 12$ & 100 \\
& None & 100 & $106 \pm 16$ \\
& MG 132 & $25 \pm 6$ & $30 \pm 11$ \\
N-starved & None & 100 & 100 \\
& MG 132 & $670 \pm 107$ & $428 \pm 130$ \\
\hline
\end{tabular}

${ }^{1}$ After seven days of growth on nutrient- rich media mycelia were transferred to media deprived of glucose (C- starvation) or $\mathrm{L}$ - asparagine ( $\mathrm{N}$ - starvation) and to trophophasic media (for details see "Materials and Methods"). Enzymatic activities were assayed after $6 \mathrm{hr}$ of exposure to the proteasome inhibitor, MG 132 (Cbz- LLLal).

2 The specific activity (per mg of protein) of samples from the parallel culture (C- deprived, N- deprived, or trophophasic) without the inhibitor was taken to be $100 \%$.
The chymotrypsin-like activity was most strongly inactivated both in starved and non-starved mycelia of this fungus. Mycelia from the non-starved cultures of $T$. versicolor retained $65 \%$ of the chymotrypsin-like activity, $78.5 \%$ of the trypsin-like activity, and $81 \%$ of the caspase-like activity after exposure to $40 \mu \mathrm{M}$ MG 132 for 6 hours. More potent inhibition was reported for the nutrient-starved mycelia of $T$. versicolor. The chymotrypsin-like activity was found to be inhibited to $31 \%$ and $36.5 \%$ in $\mathrm{C}-$ and $\mathrm{N}-$ starved mycelia, respectively.

The results shown in Table 2 demonstrate that changes in ligninolytic activities of $T$. versicolor occurred as a result of proteasome inactivation. A significant decrease in these activities was observed in C-deprived cultures, with laccase inhibited to $25 \%$ of the control activity and peroxidase inhibited to $30 \%$ of the control activity. On the other hand, the inhibitor addition under nitrogen limitation resulted in an approximately 7-fold

Table 3. Effect of in vivo proteasome inactivation on proteasome activities in mycelial extracts of Phlebia radiate

\begin{tabular}{ccccc}
\hline \multirow{2}{*}{ Culture $^{1}$} & Treatment & \multicolumn{3}{c}{ Relative activity (\% of control) $^{2}$} \\
\cline { 3 - 5 } & & $\begin{array}{c}\text { Chymotrypsin- like } \\
\text { (SucLLVY-AMC) }\end{array}$ & $\begin{array}{c}\text { Trypsin- like } \\
\text { (Z- GGR- MCA) }\end{array}$ & $\begin{array}{c}\text { Caspase- like } \\
(\text { Z- LLE- } \beta \text { NA) }\end{array}$ \\
\hline \multirow{2}{*}{ Non- starved } & None & 100 & 100 & 100 \\
& MG 132 & $46 \pm 9$ & $32 \pm 5$ & $78 \pm 7$ \\
C-starved & None & 100 & 100 & $61 \pm 11$ \\
& MG 132 & $67 \pm 6$ & $28 \pm 8$ & 100 \\
N-starved & None & 100 & $39 \pm 7$ & $52 \pm 8$ \\
\hline
\end{tabular}

${ }^{1}$ After seven days of growth on nutrient- rich media mycelia were transferred to media deprived of glucose (C- starvation) or $\mathrm{L}-$ asparagine $(\mathrm{N}-$ starvation) and to trophophasic media (for details see "Materials and Methods"). Enzymatic activities were assayed after $6 \mathrm{hr}$ of exposure to the proteasome inhibitor, MG 132 (Cbz- LLLal).

${ }^{2}$ The specific activity (per mg of protein) of samples from the parallel culture (C- deprived, Ndeprived, or trophophasic) without the inhibitor was taken to be $100 \%$. 
Table 4. Effect of in vivo proteasome inactivation on ligninolytic activities in cultures of Phlebia radiata

\begin{tabular}{cccc}
\hline \multirow{2}{*}{ Culture $^{1}$} & Treatment & \multicolumn{2}{c}{ Relative activity (\% of control) } \\
\cline { 3 - 4 } Non-starved & Laccase & Peroxidase \\
\hline \multirow{2}{*}{ C-starved } & None & 100 & 100 \\
& MG 132 & $123 \pm 36$ & $132 \pm 20$ \\
& None & 100 & 100 \\
N-starved & None & $54 \pm 17$ & $85 \pm 18$ \\
& MG 132 & $233 \pm 24$ & 100 \\
& & & $222 \pm 47$ \\
\hline
\end{tabular}

After seven days of growth on nutrient- rich media mycelia were transferred to media deprived of glucose (C- starvation) or L- asparagine ( $\mathrm{N}$ - starvation) and to trophophasic media (for details see "Materials and Methods"). Enzymatic activities were assayed after $6 \mathrm{hr}$ of exposure to the proteasome inhibitor, MG 132 (Cbz- LLLal)

2 The specific activity (per mg of protein) of samples from the parallel culture (C- deprived, N- deprived, or trophophasic) without the inhibitor was taken to be $100 \%$.

and 5-fold increase in laccase and peroxidase activities, respectively. No effect could be detected for non-starved cultures of $T$. versicolor after exposure to the proteasome inhibitor.

Table 3 summarizes the effects of proteasome inactivation on peptidase activities in mycelial extracts of Phlebia radiata. All three proteasome activities: chymotrypsin-like, trypsin-like, and caspase-like were inhibited after in vivo treatment of the fungus by MG 132. In contrast to T. versicolor, most potent inhibition was reported for the trypsin-like activity. From Table 4 it can be seen that MG 132 addition to cultures of $P$. radiata affected activity of extracellular laccase and peroxidase upon nutrient starvation. The effect of proteasome inactivation was less notable than in the case of $T$. versicolor. In C-deprived cultures, laccase and peroxidase activities were inactivated to $50 \%$ and $80 \%$ of the control activity, respectively. On the other hand, the inhibitor addition to N-starved cultures led to an approximately twofold increase in laccase and peroxidase activities. Treatment of the non-starved mycelia with MG 132 did not appreciably affect activity of these enzymes.

\section{CONCLUSIONS}

The present study showed that all distinct proteolytic activities: chymotrypsin-like, trypsin-like, and caspase-like were simultaneously detectable in mycelial extracts of the white-rot fungi Trametes versicolor and Phlebia radiata. The involvement of the $26 \mathrm{~S}$ proteasome in the cleavage of fluorogenic substrates used was strongly supported by the fact that degradation of these substrates was MgATP-stimulable. All three proteasome activities were inhibited after in vivo treatment of the fungi by MG 132 .

Because of the importance of the proteasome pathway in many aspects of cellular function, its inhibition leads to a large number of changes in the cell. Here, we observed an increase in extracellular laccase and peroxi- dase activities in N-starved cultures as a result of inhibiting proteasome-mediated proteolysis by MG132 treatment. In C-starved cultures, addition of MG 132 decreased laccase and peroxidase activities.

\section{REFERENCES}

Cabaleiro, D. R., S. Rodriguez-Couto, A. Sanroman and M. A. Longo 2002 Comparison between the protease production ability of ligninolytic fungi cultivated in solid state media. Process Biochem., 37: 1017-1023

Chen, P. and M. Hochstrasser 1995 Biogenesis, structure and function of the yeast 20S proteasome. EMBO J., 14: 2620-2630

Claiborne, A. and I. Fridovich 1979 Chemical and enzymatic intermediates in the peroxidation of o-dianisidine by horseradish peroxidase 1. Spectral properties of the products of dianisidine oxidation. Biochemistry, 18: 2324-2329

Coux, O., K. Tanaka and A. L. Goldberg 1996 Structure and functions of the $20 \mathrm{~S}$ and $26 \mathrm{~S}$ proteasomes. Annu. Rev. Biochem. 65: $801-847$

Cuervo, A. M. and J. F. Dice 1998 Lysosomes, a meeting point of proteins, chaperones, and proteases. J. Mol. Med., 76: 6-12

Dass, S. B., C. G. Dosoretz, C. A. Reddy, and H. E. Grethlein 1995 Extracellular proteases produced by the wood-degrading fungus Phanerochaete chrysosporium under ligninolytic and nonligninolytic conditions. Arch Microbiol., 163: 254-258

Datta, A. 1992 Purification and characterization of a novel protease from solid substrate cultures of Phanerochaete chrysosporium. J, Biol, Chem., 267: 728-736

Dey, S., T. K. Maiti, N. Saha, R. Banerjee and B. C. Bhattacharyya 1991 Extracellular protease and amylase activities in ligninaseproducing liquid culture of Phanerochaete chrysosporium. Process Biochem., 26: 325-329

Dosoretz, C. G., H. C. Chen and H. E. Grethlein 1990 Effect of environmental conditions on extracellular protease astivity in ligninolytic cultures of Phanerochaete chrysosporium. Appl. Environ. Microbiol., 56: 395-400

Eriksson, K.-E., R. A. Blanchette and P. Ander 1990 Microbial and Enzymatic Degradation of Wood and Wood Components. Berlin, Heidelberg: Springer-Verlag

Eriksson, K-E and B. Pettersson 1988 Acid proteases from Sporotrichum pulverulentum. Methods Enzymol., 160: 501-508

Fahraeus, G. and B. Reinhammar 1967 Large scale production and purification of laccase of the fungus Polyporus versicolor and some properties of laccase A. Acta Chem. Scand., 21: 2367-2378

Fujimuro, M., H. Takada, Y. Saeki, A. Toh, K. Tanaka and H. Yokosawa 1998 Growth-dependent change of the 26S proteasome in budding yeast. Biochem. Biophys. Res. Commun. 251: 818-823

Glickman, M. H. and A. Ciechanover 2002 The Ubiquitin-Proteasome Proteolytic Pathway: Destruction for the Sake of Construction. Physiol. Rev., 82: 373-428

Glickman, M. H., D. M. Rubin, V. A. Fried and D. Finley 1998 The regulatory particle of the Saccharomyces cerevisiae proteasome. Mol. Cell. Biol., 18: 3149-3162

Goldberg, A. L., T. N. Akopian, A. F. Kisselev, D. H. Lee and M. Rohrwild 1997 New insights into the mechanisms and importance of the proteasome in intracellular protein degradation. Biol. Chem., 378: 131-140

Hilt, W. and D. H. Wolf 1992 Stress-induced proteolysis in yeast. Mol. Microbiol., 6: 2437-2442

Jeffries, T. W., S. Choi and T. K. Kirk 1981 Nutritional regulation of lignin degradation by Phanerochaete chrysosporium. Appl. Environ. Microbiol., 42: 290-296

Keyser, P., T. K. Kirk and J. G. Zeikus 1978 Ligninolytic enzyme system of Phanerochaete chrysosporium: Synthesized in absence of lignin in response to nitrogen starvation. J. Bacteriol., 135:790-797

Kisselev, A. F., T. N. Akopian, V. Castillo and A. L. Goldberg 1999 Proteasome active sites allosterically regulate each other, sug- 
gesting a cyclical bite-chew mechanism for protein breakdown. Mol. Cell., 4: 395-402

Kisselev, A. and A. L. Goldberg 2001 Proteasome inhibitors: from research tools to drug candidates. Chem. Biol., 8: 739-758

Lee, D. H. and A. L. Goldberg 1998 Proteasome inhibitors: valuable new tools for cell biologists. Trends Cell Biol., 8: 397-403

Leonowicz, A. and K. Grzywnowicz 1981 Quantitative estimation of laccase forms in some white-rot fungi using syringaldazine as a substrate. Enzyme Microb. Technol., 3: 55-58

Lilly, W. W., R. E. Bilbrey, B. L. Williams, L. S. Loos, D. F. Venable and S. M. Higgins 1994 Partial characterization of the cellular proteolytic system of Schizophyllum commune. Mycologia, 86: $564-570$

Pickart, C. M. 1998 Polyubiquitin chains, in: J.-M. Peters, J. R. Harris, D. Finley (Eds.), Ubiquitin and the Biology of the Cell, Plenum Press, New York, pp. 19-63

Pickart, C. M. and R. E. Cohen 2004 Proteasomes and their kin: Proteases in the machine age. Nature Reviews. Mol. Cell Biol., 5: $177-187$

Rechsteiner, M. 1998 The 26S proteasome, in: J.-M. Peters, J. R. Harris, D. Finley (Eds.), Ubiquitin and the Biology of the Cell, Plenum Press, New York, 1998, pp. 147-189

Schacterle, G. R. and R. L. Pollack 1973 A simplified method for the quantitative assay of small amounts of protein in biologic material. Anal. Biochem., 51: 654-655

Seemüller, E., A. Lupas, D. Stock, J. Löwe, R. Huber and W. Baumeister 1995 Proteasome from Thermoplasma acido- philum - a threonine protease, Science, 268: 579-582

Skoda, B. and L. Malek 1992 Dry pea seed proteasome. Plant Physiol., 99: 1515-1519

Staszczak, M., E. Zdunek and A. Leonowicz 2000 Studies on the role of proteases in the white-rot fungus Trametes versicolor: Effect of PMSF and chloroquine on ligninolytic enzymes activity. J. Basic Microbiol., 40: 51-63

Staszczak, M., G. Nowak, K. Grzywnowicz and A. Leonowicz 1996 Proteolytic activities in cultures of selected white-rot fungi. $J$. Basic Microbiol., 36: 193-203

Staszczak, M. 2002 Proteasomal degradation pathways in Trametes versicolor and Phlebia radiata. Enzyme Microb. Technol., 30: 537-541

Tanaka K., T. Yoshimura and A. Ichihara 1989 Role of substrate in reversible activation of proteasomes (multi-protease complexes) by sodium dodecyl sulfate. J. Biochem., 106: 495-500

Thrower, J. S., L. Hoffman, M. Rechsteiner and C. M. Pickart 2000 Recognition of the polyubiquitin proteolytic signal. EMBO J., 19: $94-102$

Voges, D., P. Zwickl and W. Baumeister 1999 The 26S proteasome: A molecular machine designed for controlled proteolysis. Annu. Rev. Biochem., 68: 1015-1068

Wadekar, R. V., M. J. North and S. C. Watkinson 1995 Proteolytic activities in two wood-decaying basidiomycete fungi, Serpula lacrymans and Coriolus versicolor. Microbiology, 141 1575-1583 